\title{
REPOSITIONING AGED HEALTHCARE AS A PREFERRED CAREER OPTION FOR NURSING STUDENTS: LESSONS FROM THE LITERATURE
}

\author{
Cath Fraser, Judith Honeyfield and Mary White
}

\section{INTRODUCTION}

The global rise in longevity means that older people are making a growing demand on the health sector around the world, yet specialist training in aged healthcare attracts fewer applicants than almost any other area (Gawande, 2014), and the supply of "personnel to meet the demand is not projected to keep pace" (King et al., 20II, p. 9). So what do nursing and healthcare students need to know, and to be, in order to provide exemplary services to older people? And, how should we be guiding higher education programme development to ensure that healthcare of older people is viewed as an attractive and valued career choice? The drive to answer these two questions became the catalyst for the research project reported in this literature review.

In Aotearoa New Zealand our healthcare services face this same challenge of a burgeoning older population and a shortfall of qualified practitioners - but we can also make a significant contribution to the discussion, drawing on an environment which promotes health, physical activity and wellbeing, as well as our unique bicultural heritage which blends indigenous and Western perspectives on how we respect and support older people.

Aotearoa New Zealand is widely recognised internationally for its universal healthcare and culturally responsive healthcare provision (Gauld, 2020; Ministry of Health, 2014). These are some of the reasons that our institute of technology - as a subsidiary of Te Pukenga: New Zealand Institute of Skills and Technology - was recently approached by a number of Chinese higher education providers, including universities and teaching hospitals, to progress teaching, learning and research collaborations in aged healthcare education.

The plan is that, together, our respective organisations will develop a Sino-New Zealand programme to prepare and credential students within a culturally responsive teaching and learning context, to address the challenges of catering for this rapidly growing population segment. The first step towards this goal has been the completion of a substantive integrative literature review of good practice reports regarding aged healthcare provision. The New Zealand and Chinese partners identified three inter-related strands of particular interest, 'Wellness,' 'Culture' and 'Education.' This paper reports on the lessons and good practice indicators outlined in the literature relevant to the third domain - education - and the focus questions in the first paragraph above which guided our study.

\section{METHODOLOGY}

The integrative literature review research method enabled the researchers to summarise literature from diverse sources, including published and 'grey' (non-academic) literature and contemporary commentary (Broome, 2000). This approach allows multiple perspectives in defining concepts, reviewing theories, considering evidence, 
identifying gaps in the literature and recognising the applicability of all of these to policy and practice (Whittemore \& Knafl, 2005). As Broome notes, "the primary purpose of a review of existing knowledge, usually in a large part the literature, is to gain an in-depth understanding of a phenomenon by building on the work of others" (p. 23I).

Potential sources of accounts of good practice in aged care were largely identified through databases accessed via the EBSCO Discovery search engine, which includes multiple medical, nursing and health databases and individual e-journal subscriptions. Google Scholar was used to find full-text articles and others were sourced through our organisation's library interloan system. Most searches were conducted by first seeking Aotearoa New Zealand and Australian studies. Keywords used in the searches related to wellbeing included terms like "aged health," "aged care," "active retirement," "positive aging" and "good practice." In the sections relating to culture and education, these terms were often paired with other keywords, including "Māori," "biculturalism," "kaupapa," "kaumatua" and "qualifications," "nurse education," "career," "carer," "healthcare assistant." Literature was generally excluded if older than 20 years.

Sources were logged in an Excel spreadsheet, using a series of headings based on Booth's (2006) SPICE framework: Setting; Perspective; Intervention; Comparison; Evaluation. Next, we added subheadings - for example, "Setting" included "country," " population/ethnicity," "private/public hospital," "residential care/independent living," "community" and "agency," as shown in Figure I. This tool enabled easy access across the team and assisted us to cross-reference accounts for document analysis, conducted under the three broad categories of "wellness," "culture" and "education." Importantly, all this material was viewed through a cultural lens (Hardin et al., 20I4), which separated mainstream and Westernised accounts from indigenous and smaller population studies.

\begin{tabular}{|c|c|c|c|c|c|c|}
\hline Setting & Perspective & Intervention & Comparison & Evaluation & Cultural lens & Strand \\
\hline Country & Nurse & $\begin{array}{l}\text { Clinical / } \\
\text { procedural }\end{array}$ & Control group & $\begin{array}{l}\text { Qualitative / } \\
\text { quantitative }\end{array}$ & OECD & Wellness \\
\hline $\begin{array}{l}\text { Population/ } \\
\text { ethnicity }\end{array}$ & $\begin{array}{l}\text { Caregiver / } \\
\text { healthcare } \\
\text { assistant }\end{array}$ & $\begin{array}{l}\text { Education / } \\
\text { training }\end{array}$ & $\begin{array}{l}\text { Cohorts - by } \\
\text { year or region }\end{array}$ & Sample size & Western & Culture \\
\hline $\begin{array}{l}\text { Private/public } \\
\text { hospital }\end{array}$ & $\begin{array}{l}\text { Medical - GP, } \\
\text { specialist }\end{array}$ & $\begin{array}{l}\text { Personnel } \\
\text { - buddy / } \\
\text { mentor }\end{array}$ & Inter-agency & $\begin{array}{l}\text { Research design / } \\
\text { methodology }\end{array}$ & $\begin{array}{l}\text { Non- } \\
\text { Western } \\
\text { mainstream }\end{array}$ & Education \\
\hline $\begin{array}{l}\text { Residential } \\
\text { care/ } \\
\text { independent } \\
\text { living }\end{array}$ & $\begin{array}{l}\text { Student } \\
\text { (including } \\
\text { placements); } \\
\text { graduate }\end{array}$ & $\begin{array}{l}\text { External } \\
\text { advisors } \\
\text { (cultural, } \\
\text { language) }\end{array}$ & $\begin{array}{l}\text { Different } \\
\text { providers }\end{array}$ & $\begin{array}{l}\text { Multiple } \\
\text { participant } \\
\text { groups }\end{array}$ & Indigenous & \\
\hline Community & $\begin{array}{l}\text { Management/ } \\
\text { leadership }\end{array}$ & & International & & Māori & \\
\hline Agency & & & & & Pasifika & \\
\hline
\end{tabular}

Figure I. The Sino-New Zealand aged healthcare research team's SPICE framework for collating review sources. 


\section{RESEARCH DESIGN - THE CULTURAL LENS APPROACH}

The overarching research design adopted for this review is the cultural lens approach, a model widely used in psychology, which offers a way to evaluate how theories, practices or phenomena apply across cultural groups (Hardin et al., 2014). The cultural validity of outcomes and/or models is therefore about "the extent to which aspects of theories are generalizable across, equally relevant to, or equally useful to diverse groups" (Hardin et al., 2014, p. 656). Another way of describing this concept is offered in a photography metaphor:

Culture acts like the coloured lens that a photographer uses to see a landscape in a particular way, or the wide-angle lens that both captures and distorts reality. The universal behaviour patterns remain, but they are coloured and bent by the cultural environment. (Ryan, 2017, para. 5).

The cultural lens approach follows five steps (paraphrased from Dik et al., 2019) and Hardin et al. (2014):

I. Articulate how central constructs have been defined (implicitly or explicitly) and thus operationalised in past research.

This step is about stating and exploring conceptual definitions and processes related to the topic - nursing education curricula, nursing educators' beliefs and student nurses' experiences of learning about aged healthcare.

2. Identify the groups (a) from which these definitions have been derived and (b) to which the constructs have either not been applied or with which surprising results have been found.

This step identifies the cultural group(s) of interest and the group(s) from which the theory was originally derived. It considers previous studies such as reviews of nursing education curricula development, recognising that almost all have been situated in a Western healthcare system. The literature in Aotearoa New Zealand which directly addresses the two cultural groups of Māori and non-Māori nursing students is still comparatively small.

3. Identify relevant dimensions underlying cultural variability: What do we know about the cultural contexts of Groups A and B?

This step begins by acquiring basic cultural knowledge and considers sources of cultural variability without yet making conceptual connections to the theory, avoiding easy or 'intuitive' assumptions. In Aotearoa New Zealand we are fortunate to have a large and growing body of scholarship relating to the enactment of biculturalism in healthcare provision to draw on as we considered how best to explore the gap identified in Step 2 above.

4. Evaluate the definitions/operationalisations of the central constructs (from Step I) in the context of broader cultural knowledge about those groups (from Step 3): What do we know about the topic concept within the cultural context of Group B?

This step entails a synthesis of the previous steps, seeking to connect and explain differences. What do these differences mean? We were able to find several areas in which there appeared to be some tension between the direction offered by a European tradition of aged healthcare and an indigenous sense of cultural identity. At this point we were consciously moving from knowledge to implications, which in this study highlighted areas of cultural safety - mostly but not always in practicum placements, rather than the classroom.

5. Derive research questions and specific hypotheses based on the questions and answers from Step 4 .

This final step seeks to develop directions for new research and/or practice, based on the insights gained from the cultural lens approach process. Directions indicated for the present inquiry include addressing potential areas of cross-cultural misunderstandings with changes in curricula delivery, practicum placement assessment criteria, and targeted professional development initiatives with host placement providers. 
The rationale for adopting the cultural lens tool to guide our literature review was multi-faceted. First, our Chinese partners were keen to learn more about bicultural delivery and how to incorporate diversity into healthcare delivery. Podsiadlowski and Fox (20II) describe how "New Zealand has a particularly unique and compelling cultural landscape, with an indigenous population coexisting civilly if inequitably with the postcolonial European population for two centuries" (p. 5). This situation means, they say, that Māori and non-Māori have very different world views. In addition, we now have numerous other ethnicities, and so Aotearoa New Zealand must be considered multicultural as well as bicultural - again, an area of interest to our Chinese association members.

Second, as noted above, Māori are disadvantaged compared to non-Māori in many spheres of life, including healthcare access and outcomes. Māori have a lower life expectancy (a gap of approximately 7 years) a higher incidence of smoking, hazardous drinking and obesity. Māori health status is also unequal across almost all chronic and infectious diseases, as well as injuries, including suicide (Health Quality and Safety Commission of New Zealand (HQSC), 2019). Health equity is therefore an important governmental focus (Ministry of Health, 2014; Ministry of Justice, 2016), and nursing graduates need key understandings of the causes and consequences of the cultural divide to address this situation as registered practitioners in the workplace.

Third, reducing inequity is a core driver behind our tertiary sector's emphasis on ensuring that programmes and qualifications model active and meaningful Māori /Crown partnerships, as described in Te Pūkenga - New Zealand Institute of Skills and Technology's Te Pae Tawhiti: Tiriti o Waitangi Excellence Framework (Te Pükenga, 2020). The five underpinning goals (greater relevance of provision, better equitable access, stronger Māori participation, more equitable outcomes, and stronger responsive practices) all require an understanding of cultural differences and cultural identity. In addition, Māori comprise 43 percent of our institute's student body and usually 25-33 percent of our nursing student intake (Toi Ohomai, 2021); in addition, the Bay of Plenty region, which is the setting for this study, ranks third of the 16 regions in Aotearoa New Zealand for Māori population (Statistics New Zealand, 2014). Clearly, this organisation and our teaching staff in nursing and community health programmes have plenty of reasons to be engaged in research which focuses on a cultural explanation of what works and what doesn't - in aged healthcare and in aged healthcare education.

Finally, in using the cultural lens approach it is important to recognise and clarify the ambiguity which can accompany the use of the term culture. In anthropological studies, culture groups are often considered according to geographic, national, racial and linguistic characteristics (Hardin et al., 2014). In global studies, culture is more about identity, or what Hofstede et al. (20I0) calls "the software of the mind" and the United Nations (20I2) see as including concepts like social inclusiveness and rootedness, resilience, creativity and the use of local resources, skills and indigenous knowledge. Cultural factors encompass the social, political and economic, influencing lifestyles, individual behaviour, consumption patterns, values and our interaction with the natural environment. According to Soini and Dessein (2016), multiple understandings of culture can co-exist simultaneously, and the context is all important: culture can be "mono-, multi-, inter-, or transdisciplinary" (p. 8). Statistics New Zealand (2009) offers a local and official definition:

Culture can be defined as a general way of life that contributes to national identity and society. Culture can also be defined as the shared knowledge, values, and practices of specific groups. People's identity may relate to their ethnicity, gender, sexual orientation, religious and spiritual beliefs, or physical, artistic, and cultural activities ...

Cultural expression and participation contribute to individual well-being and sense of belonging. The expression of, and respect for, cultural practices, language, and beliefs is part of a socially cohesive society. These expressions of culture are sustained by being passed down generations, and through the protection of heritage. (p. 127) 
As this review draws on both governmental and academic documents, and focuses on the Aotearoa New Zealand setting, the use of the term culture will most closely align with this last description. Considering culture as a way of life within the cultural lens approach, then, allowed us to scan and sort the sources in our iterative literature review according to their intrinsic 'fit' with our bicultural environment. From this starting point, we then derived a series of broad fields of good practice within our three target strands (wellness, culture, education). The next section outlines our findings related to education.

\section{FINDINGS}

Ten fields of good practice in higher education provision related to aged healthcare were identified. Each of these draws on literature from across the various review sources, and is included, following consideration through a cultural lens, in terms of its valorisation of equity, empowering learners, and strengthening the perception of aged healthcare as a desirable graduate career path. The following summary briefly introduces each field, and lists associated good practice indicators identified from the review.

\section{Combating ageism}

Age and ageism are socially constructed. Fisher (2018) describes how old age is frequently defined in one of two ways: "either from a positive paradigm of wisdom, influence and worthy of respect; or from a perspective of ageing as a deficit with significant physical and mental deterioration that is irreversible and undesirable" (p. 6I). An associated good practice exercise in higher education is:

- Structured sessions to raise student awareness of their own ageist attitudes / unconscious bias and potential impact of these in the workplace.

\section{Promoting aged healthcare as a preferred area of practice}

Ageism is linked not only to the individual, but also to their treatment and environment. Healthcare students frequently express concerns that community aged healthcare settings, with their low-tech character and lack of rigour compared to hospital positions, will mean that their education and high-tech skills are underutilised and potentially lost (Wilkinson et al., 2016). Recommendations from the literature to reverse such perceptions include:

- Challenging the concept of low-tech caring and compassion nursing as a less prestigious calling than high-tech, acute hospital roles

- Having positive, enthusiastic and knowledgeable guest lecturers from the field as role models.

\section{Ensuring that older adults are constructed positively in education curricula}

Attitudes toward older people have an important effect on the quality of care provided by nurses and other healthcare professionals, as well as on patient experience and employment preferences. Gerontological nursing education has been reported as a key factor that influences students' attitudes toward older people (Hsu et al., 2019). Good practice suggestions include:

- Constructing the older person as a unique individual (not a stereotype) and emphasising diversity across this demographic

- Offering an integrated approach in which healthcare for older adults is woven through all semesters and topics.

\section{A holistic, rather than medicalised view of older people}

People at all ages of the lifespan are the product of their culture, context and experiences and a discourse related to their medical attributes is inevitably partial. Better practice identified in the literature includes: 
- Modelling and exploring a postmodernist view of ageing as a social, rather than scientific construct

- $\quad$ Providing holistic training which includes physiological, psychological and sociological dimensions of knowledge about ageing

- Using surveys (including pre- and post-placement) about knowledge and perceptions of older people identifies gaps and can challenge students' stereotypes with facts, statistics and published study outcomes.

\section{Teaching history to understand current practice}

Teaching history as a designated topic area to healthcare students is suggested by several authors: first, to strengthen and enrich a sense of professional identity and, second, to further develop critical thinking skills by questioning myths and supposed truisms, including those about colonialism and settlement, from the past (Madsen, 2008; Podsiadlowski \& Fox, 201 I). Good practice indicators in education provision are:

- Teaching a critical history of nursing to build professional identity and encourage challenging of stereotypes

- Teaching Te Tiriti o Waitangi as a living document and supporting learners to make both a personal and professional practice connection.

\section{Teaching empathy and respect}

The Nursing Council of New Zealand (NCNZ) (2012) emphasises importance of the healthcare worker-patient relationship and communication - two further examples of soft skills which may not be science, but are nonetheless essential to healthcare practice. NCNZ's (2012) Code of Conduct outlines eight principles underpinning professional conduct; the first of these is "Respect the dignity and individuality of health consumers" (p. 6). Standards I.I and I.3 relating to "dignity" and active listening are particularly relevant to educating students in ways that will combat ageism and support a positive construction of older people in the healthcare system. Suggested good practice includes the following:

- Educators must role-model and teach the components of empathy and respect - students absorb 'bedside manner' from observation

- Content should include the moral responsibility of nurses to ensure that older people's needs and wishes are respected, even when patients have diminished ability to express these themselves.

\section{Twenty-first-century pedagogy}

An important element of good practice in modern curricula design is the inclusion of a wide range of activities to suit the diversity of learners in our contemporary classrooms; factors to be considered include cultural background, learning needs and preferences, prior knowledge and learning experiences, goals and motivation. Rivierea et al. (2019) advocate activities which focus on people, rather than conditions, to foreshadow clinical placements. Examples are:

- Teaching metacognitive skills - focus on how to learn, rather than content

- Active and learner-centred, with a wide range of activities to suit student diversity

- Preparation for placement with activities which emphasise communication: e.g., scenario-based learning, role plays, analysing videos of patient-nurse contact, simulations

- Using a thematic approach to interweave past, present, political and personal perspectives of a topic

- Use of tutorials for participatory group work

- Use of primary source material to promote critical reflection and questioning

- Regular, condensed set readings linked to end activities. 


\section{Effective clinical placements}

As Fergusson (2019) notes, "the lay person enrols on the programme to learn how to be a nurse and exits the programme with a degree qualification. The subtle distinction of doing nursing or being a nurse is played out in structure[ed] learning" (p. 124), including both classroom and practice settings, where the student learns "to think like, act like, and be a nurse" (p. 125). Literature which specifically considers clinical placements in aged care settings emphasises the impact that this experience can have in combating ageism and shifting students' attitudes towards older people (Rodgers \& Gilmour, 20II). Identified good practice includes:

- Aged healthcare placements often occur early in a training programme for all-round interpersonal and skill development, but benefits are consolidated by a second placement towards the end of training

- Students already working in paid employment in aged care maximise the benefits offered by clinical placements

- Assigned buddies can assist students' integration into a healthcare workplace, so long as the informal 'mentor' has skills, experience and strong professional practice in the aged care sector

- The preceptor-student relationship comprises personal, interpersonal, organisational and policy dimensions, and is a shared responsibility between educational institution, workplace site and student

- Placements are an ideal setting for interprofessional learning with students from other healthcare disciplines

- Prepare students for placement by teaching self-efficacy skills, including technical, practical and emancipatory reflection models and critical thinking

- Continuing professional development for new graduates working in aged care improves competence and confidence, and should be promoted to both students and healthcare providers

- Reflective journals during placement assist with timely feedback and create a resource for post-placement peer learning and debriefing

- Practical placements should be in student-friendly facilities, open to new approaches, where staff model enthusiasm and people-centered care.

\section{Promoting aged and palliative care as a specialism}

Many studies cited in this review note the low level of esteem too frequently assigned to aged healthcare and those who work there (e.g., Fisher, 20 I8; Parker et al., 202I). In consequence, there is a growing call by commentators (e.g., Gawande, 20I4; Rodgers \& Gilmour, 20I I) for a paradigm shift. These authors advocate that aged healthcare (or "gerontology" or "geriatric medicine") be established as a specialism for healthcare students, with dedicated instructors and collaboration with specialist care facilities. A summary of this position is:

- An emphasis on the advanced knowledge and specialist skills is required to shift negative perceptions of working in this area. This can be addressed by creating nurse specialist training, qualifications and professional identity.

\section{Embedding culture in the curriculum}

Healthcare in modern-day Aotearoa New Zealand is committed to meeting its obligations under Te Tiriti o Waitangi to achieve the best health outcomes for Māori. NCNZ's (2020) Te Tiriti o Waitangi Policy Statement provides high-level direction for working with iwi and Māori, including the implementation of He Korowai Oranga - New Zealand's Māori Health Strategy \& Action Plan (Ministry of Health, 2014) and the concept of cultural safety. This commitment is threaded through the Nursing Council's standards for the nursing profession, and is therefore integral to education curricula preparing nurses and healthcare workers for professional practice. Some helpful practice suggestions described in recent studies, including LiLACS NZ (2017), are:

- Cultural inclusivity and content are woven through the curriculum, rather than taught discretely

- Cultural competence and cultural safety are deconstructed; students are able to relate these concepts to their own assumptions and world views, and to understand the impact of these on their practice and workplace relationships

- Active recruitment and retention of Māori students via enabling strategies including increasing the number of Māori teaching staff, ensuring cultural relevance within the curriculum and providing safe learning environments 
- $\quad$ Active recruitment and retention of male students via enabling strategies including increasing the number of male teaching staff and challenging gender-based stereotypes about healthcare occupations and roles

- Ensure international students are treated equitably by providing enrolment, pastoral and academic support, and dispelling stereotypes.

\section{CONCLUSION}

The shift from profiling older people as frail, needy and disproportionate users of health services to positive contributors to, and participants in, their community has been building over the last two decades or so. Government policies both reflect and drive these attitudes towards healthy aging and wellness, and higher education curricula must do the same. This paper has offered indicators of good practice gleaned from an extended literature review, points which are intended to inform programme development for an aged healthcare qualification, as part of a SinoNew Zealand partnership initiative. It is hoped that these findings may also be of interest to other healthcare education providers. The key contribution we hope that this paper makes to our sector is the application of the cultural lens approach as a useful tool for evaluating strategies and suggestions from the literature. The ultimate goal is that healthcare education related to care of the aged is built on a framework which advances equity and respect - for learners, graduates and the people they will be looking after. In this way, we hope, caring for our older members of society will come to be viewed as a rich and rewarding career path; a professionally satisfying life-work which advances all of our wellbeing.

Cath Fraser is a faculty research coordinator at Toi Ohomai Institute of Technology. She is interested in coaching and mentoring, collaborative and interdisciplinary research and internationalisation.

(10 https://orcid.org/0000-000I-5355-7660

Judith Honeyfield teaches on the Bachelor of Nursing at Toi Ohomai Institute of Technology, supporting Year three students during their practice placements in primary healthcare and community settings. Her research interests include partnership-based relationships between education and practice, and quality improvement.

(10 https://orcid.org/0000-0001-8045-6857

Mary White is a senior academic staff member in the Bachelor of Nursing at Toi Ohomai Institute of Technology, with an interest in incorporating mātauranga Māori and cultural responsiveness into educational practice.

(1D) https://orcid.org/0000-0003-4722-94II

\section{REFERENCES}

Booth, A. (2006). Clear and present questions: Formulating questions for evidence based practice. Library Hi Tech, 24(3), 355368. https://doi.org/10.1108/07378830610692127

Broome, M. E. (2000). Integrative literature reviews for the development of concepts in nursing. In B. Rodgers \& K. Knafl (Eds.), Concept development in nursing: Foundations, techniques and applications (2nd ed., pp. 23I-250). W. B. Saunders.

Dik, B. J., Canning, B. A., \& Marsh, D. R. (2019). A cultural lens approach to promoting work as a calling. In L. E. Van Zyl \& S. Rothmann Sr. (Eds.). Positive psychological intervention design and protocols for multi-cultural contexts. Springer.

Fergusson, D. (2019). What are the elements of work readiness of new graduate nurses in the New Zealand context? A professional consensus [Doctor of Health Science thesis, Auckland University of Technology].

Fisher, S. (2018). Factors that influence nurses' attitudes towards working with older adults: A qualitative descriptive study [Master of Health Science thesis, Auckland University of Technology].

Gauld, R. (2020). New Zealand. In R. Tikkanen, R. Osborn, E. Mossialos, A. Djordjevic, \& G. A. Wharton (Eds.), International health care system profiles. International Commonwealth Fund. https://www.commonwealthfund.org/international-healthpolicy-center/countries/new-zealand 
Gawande, A. (2014). Being mortal: Medicine and what matters in the end. Doubleday Canada.

Hardin, E. E., Robitschek, C., Flores, L. Y., Navarro, R. L., \& Ashton, M. W. (2014). The cultural lens approach to evaluating cultural validity of psychological theory. American Psychologist, 69(7), 656-668. https://doi.org/l0.1037/a0036532

Health Quality and Safety Commission of New Zealand (HQSC). (2019). A window on the quality of Aotearoa New Zealand's health care 2019 - a view on Māori health equity. HQSCNZ.

Hofstede, G., Hofstede, G. J., \& Minkov, M. (20I0). Cultures and organizations: Software of the mind (3rd ed.). McGraw Hill Professional.

Hsu, M. H. K., Ling, M. H., \& Lui, T. L. (2019). Relationship between gerontological nursing education and attitude toward older people. Nurse Education Today, 74, 85-90.

King, A., Boyd, M., Carver, P., \& Dagley, E. (201I). Evaluation of a gerontology nurse specialist in primary health care: Case finding, care coordination and service integration for at-risk older people. Ministry of Health. https://www.health.govt.nz/system/files/ documents/publications/evaluation-of-a-gerontology-nurse-specialist-in-primary-health-care.pdf

LiLACS NZ. (2017). Intervals of care need: Need for care and support in advanced age: LiLACS NZ. Ministry of Health. https://www. health.govt.nz/publication/intervals-care-need-need-care-and-support-advanced-age-lilacs-nz

Madsen, W. (2008). Teaching history to nurses: Will this make me a better nurse? Nurse Education Today, 28, 524-529.

Ministry of Health. (2014). The guide to He Korowai Oranga: Māori Health Strategy 2014. Ministry of Health.

Ministry of Justice. (2016). The principles of the Treaty of Waitangi as expressed by the courts and the Waitangi Tribunal. Ministry of Justice. https://www.waitangitribunal.govt.nz/treaty-of-waitangi/principles-of-the-treaty

Nursing Council of New Zealand. (2020). Te Tiriti o Waitangi policy statement. https://www.nursingcouncil.org.nz/Public/Treaty_ of_Waitangi/Te_Tiriti_o_Waitangi_Policy_Statement/NCNZ/About-section/Te_Tiriti_o_Waitangi_Policy_Statement. aspx?hkey=e0 Ib23f4-2e87-43e0-9e89-cb50f7b1929d

Nursing Council of New Zealand. (2012). Code of conduct for nurses. https://www.nursingcouncil.org.nz/Public/Nursing/Code_ of_Conduct/NCNZ/nursing-section/Code_of_Conduct.aspx

Parker, C. N., Harvey, T., Johnston, S., \& MacAndrew, M. (2021). An exploration of knowledge of students and staff at residential aged care facilities and implications for nursing education. Nurse Education Today, 96, 104639. https://doi.org//0.1016/j. nedt.2020.104639

Podsiadlowski, A., \& Fox, S. (201 I). Collectivist value orientations among four ethnic groups: Collectivism in the New Zealand context. New Zealand Journal of Psychology, 40(I), E5-18.

Rivierea, M., Dufoortc, H., Van Heckead, A., Vandecasteelea, T., Beeckmana, D., \& Verhaeghea, S. (2019). Core elements of the interpersonal care relationship between nurses and older patients without cognitive impairment during their stay at the hospital: A mixed-methods systematic review. International Journal of Nursing Studies, 92, 154-172.

Rodgers, V., \& Gilmour, J. (20II). Shaping student nurses' attitudes towards older people through learning and experience. Nursing Praxis in New Zealand, 27(3), 13-20.

Ryan, C. (2017, April 12). Through the looking glass: A cultural lens on behaviour change. StopPress, ICG Media. https://stoppress. co.nz/opinion/through-looking-glass-cultural-lens-behaviour-change/

Soini, K., \& Dessein, J. (2016). Culture-sustainability relation: Towards a conceptual framework. Sustainability 2016. MDPI. Google Scholar. https://scholar.google.co.nz/scholar?q=Culture-sustainability+relation+soini+dessein\&hl=en\&as_sdt=0\&as_ vis $=\mid \&$ oi=scholart

Statistics New Zealand. (2014). 2013 Census QuickStats about people aged 65 and over. Statistics New Zealand. https://www.stats. govt.nz/assets/Uploads/Retirement-of-archive-website-project-files/Reports/20I3-Census-QuickStats-about-peopleaged-65-and-over/2013-census-qs-65-plus.pdf

Statistics New Zealand. (2009). Measuring New Zealand's progress using a sustainable development approach: 2008. Statistics New Zealand.

Te Pūkenga. (2020). Te Pae Tawhiti - 2020 to 2025 [Working draft] Te Tiriti O Waitangi excellence framework. Te Pūkenga. https:// xn--tepkenga-szb.ac.nz/

Toi Ohomai Institute of Technology. (2021). Annual report 2020. Toi Ohomai Institute of Technology. https://www.toiohomai. ac.nz/about/annual-report

United Nations. UN System Task Team on the Post-20I5 UN Development Agenda. (2012). Culture: A driver and an enabler of sustainable development: Thematic think piece. United Nations. https://www.un.org/millenniumgoals/pdf/Think\%20 Pieces/2_culture.pdf

Whittemore, R., \& Knafl, K. (2005). The integrative review: Updated methodology. Journal of Advanced Nursing, 52(5), 546-553.

Wilkinson, J., Neville, S., Huntington, A., \& Watson, P. (2016). Factors that influence new graduates' preferences for specialty areas. Nursing Praxis in New Zealand, 32(1), 8-19. 